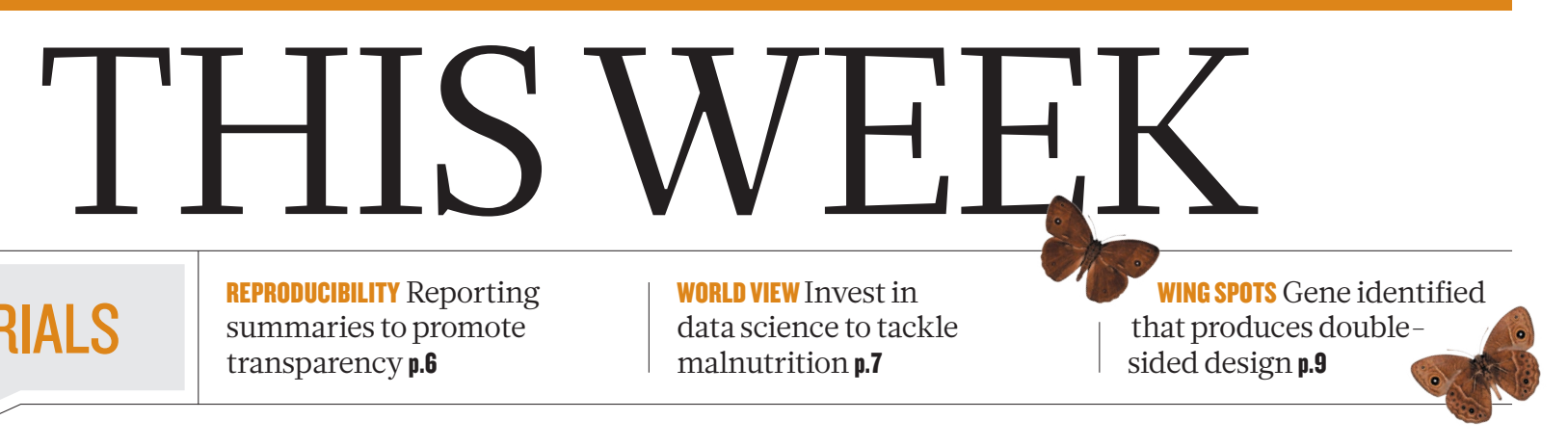

EDITORIALS summaries to promote aries to prom transparency $\mathbf{p . 6}$
LD VIEW Invest in malnutrition $\mathbf{p . 7}$ that produces doublesided design $\mathbf{p} .9$

\title{
How to be good
}

\section{A proposed international code of ethics can serve as a springboard for discussion on how scientists can take positive action in their own workplace.}

Y ou are an early-career scientist poised to publish a paper that you think will be your big break. It describes your imaginative hypothesis - a potential scientific insight with substantial implications - along with the experiments you designed and constructed, and the carefully documented data that support your initial insight. It's a genuine advance for the field and will be widely cited. Your lab head will be satisfied. Job done!

Then, disaster. You wake in the small hours and realize a possible flaw: another way in which the data could be interpreted, that would throw the conclusion into doubt. No one else will spot the problem - the lab head is too busy and no editor or reviewer will realize - and further experiments to settle the issue will take time. Worse, fresh results could sink the hypothesis (and subsequent grants). So, do you publish anyway?

Of course not! Science puts the pursuit of truth above all else, right? Well, not always. The dilemma above is a real one faced by real scientists, and not all of them jump the right way. What can help them to make the right decision? Some scientists think it might help to discuss this idea: "Pursuing the truth means following the research where it leads, rather than confirming an already formed opinion."

That statement opens one of seven presentations in a 'Code of Ethics for Researchers' produced by a group of scientists convened by the World Economic Forum. These scientists, drawn from many countries, are all under 40 but well established in career terms, with decades of research and leadership ahead of them. This combination makes them well qualified to explore the realities and pressures of modern lab life, so their ideas deserve to be considered by the scientific community.

Many science organizations have issued similar recommendations to their own research communities - the Science Council of Japan, for example, has made a valiant effort. But it can be difficult to persuade busy and pressured scientists to take notice of such guidelines, especially when - usually — they are expressed in rather terse form, as if on tablets of stone. This document, carrying the weight of an international consensus, demonstrates well how consideration of ethical issues is not additional to research practice, but an integral and essential component. It has the virtue of being presented in an engaging and persuasive style.

Each of the seven pages is headed by an exhortation such as "Minimize harm" and "Support diversity", backed by an explanation of why the entreaty matters and a brief presentation of the ultimate goal and practical approaches to achieving it. A collection of real-life anecdotes helps to illustrate their relevance.

The effort is valuable because, alongside fundamental tenets of research behaviour (such as "Be accountable" and "Be a mentor"), the code contextualizes natural sciences in a time of rapid technological change and popular questioning of expertise. Its authors see it as helping to redefine "the social and moral contracts that bind researchers to society" and infuse research with "the most irreproachable behaviours".

Some of this context is familiar: it is hardly original to seek to minimize harm to citizens (ranging from wasted public money to damage to health and the environment), or to say that engaging with the public is important. But there are more radical suggestions, too: that such engagement should sometimes include public involvement in the "identification of the question, conception of a project, discussion of results and dissemination". Some will see that as extreme. Yet many research projects fail to make the societal impacts they aim for because they lack precisely this depth and breadth of engagement.

Any well informed reader will spot ways in which this code is conten-
"Consideration of

ethical issues is not additional to research practice, but an integral and essential component." Who in the real world, critics might scoff, would be willing to divert funding from postdoctoral posts into better training for principal investigators or other means by which the code can be better pursued?

As the authors state, their purpose is to stimulate open conversations "to safeguard a positive and sound research environment". Accordingly, Nature readers may do themselves and others some good by visiting http://wef.ch/coe and providing feedback. Even better, they might discuss the ideals expressed, and consider how to live up to them in their own lab, research institution or funding agency. We at Nature are trying to do so, too.

\section{Wasted energy}

\section{Oil and gas emissions could exceed current estimates - and governments need to act.}

W hen it comes to harmful emissions from the oil and gas industry, much of the focus tends to fall on methane, a potent greenhouse gas. But ethane and propane deserve scrutiny too.

Scientists know that ethane emissions rose during the early twentieth century and then began to decline in the 1970s as modern air regulations took effect. More recent monitoring suggests that the trend reversed in 2009, when atmospheric concentrations again began to rise, probably due to emissions from the expanding oil and gas industry, and particularly in the United States. Yet reconciling the atmospheric data with current emissions inventories has been tough. 